\title{
PROCESS ANALYSIS OF THE HOT PLATE WELDING OF DRIVE BELTS
}

\author{
Krzysztof WALĘSA, ${ }^{*}$ Ireneusz MALUJDA, ${ }^{*}$ Krzysztof TALAŚKA, ${ }^{*}$ Dominik WILCZYŃSKI ${ }^{\star}$ \\ *Institute of Machine Design, Poznań University of Technology, ul. Piotrowo 3, 61-138 Poznań, Poland \\ krzysztof.walesa@put.poznan.pl, ireneusz.malujda@put.poznan.pl, \\ krzysztof.talaska@put.poznan.pl, dominik.wilczynski@put.poznan.pl
}

received 11 February 2020, revised 25 May 2020, accepted 28 May 2020

\begin{abstract}
Most industrial machines use belt transmission for power transfer. These mechanisms often use the round belts of several millimetres in diameter that are made of thermoplastic elastomers, especially polyurethane. Their production process calls for bonding the material, which is often performed by hot plate butt welding. In order to achieve proper design of an automatic welding machine, the authors analysed the hot plate welding process of round belts. This process consists of five phases. It is necessary to recognize all the physical phenomena that occur during welding, especially those connected with thermomechanical properties of material. This knowledge is necessary to determine the temperature distribution during each step of the process. The paper presents a standard welding cycle together with an explanation of the physical phenomena in each phase. An analysis of these fundamentals will be used to derivate the function of temperature distribution during all process phases. In addition, some assumptions for calculation of temperature distribution and some fundamental physic correlations were presented.
\end{abstract}

Keywords: Hot plate welding, round drive belts, heating, thermal conducting, plasticizing

\section{INTRODUCTION}

Industrial grade belts, both used in drives and conveyors, are commonly utilized in machine building for transferring torque between the connected workstations or for transporting products on manufacturing lines. Both full cross-section and perforated conveyor belts are utilized in transportation, especially the latter are present in vacuum transportation of light objects (Wojkkowiak et al., 2018; Wojtkowiak and Talaśka, 2019; Wilczyński, 2019). The most commonly used types of drive belts are flat, toothed and shaped belts. Toothed belts are used both in simple transmissions as well as non-classical solutions, for example, with variable ratios (Domek and Dudziak, 2011; Domek et al., 2016; Krawiec et al., 2018; Krawiec et al., 2019). Shaped belts, in particular V-shaped and round belts, are commonly employed in drives, that is, special robotic arm joint mechanism, with two twisted small diameter belts (Inoue et al., 2016), they can be made of rubber (Kukla et al., 2015) or polyester or polyurethane based elastomers (Behabelt, 2015). Their common application in industrial machines calls for an efficient manufacturing process, which usually takes place in two stages (Sikora, 1993). First of all, a long belt is manufactured and cut down to required size. Finally, the ends are joined permanently to form a continuous loop (Wałęsa, 2018).

Due to the peculiar characteristics of thermoplastic elastomers used in the manufacturing of such belts, it is possible to join them by hot welding (Groover, 2015). A specific approach to this process is butt-welding utilizing the hot plate method; it is popular due to its simplicity and efficiency (Grewell and Benatar, 2007; Yousepour et al., 2004). This method is commonly employed in the automotive industry and civil engineering, for example, in the process of joining: tanks for utility fluids, lamp enclosures, engine instrumentation (Pietrzak et al., 2019; Grewell and Benatar, 2007) and pipes (Rzasinski, 2017; Troughton, 1997; Cocard et al., 2009). Furthermore, studies were carried out on the hot welding of inflexible polymer materials, for example, acrylonitrile butadiene styrene copolymer (ABS) (Mokhtarzadeh and Benatar, 2012), polycarbonate (PC) (Krishnan and Benatar, 2004), as well as polypropylene (PP) (Nieh and Lee, 1992). However, it needs to be pointed out that all of them apply primarily to plastics.

The authors started design work on a device for automated butt welding of drive belts utilizing the hot plate technique, which is to improve the efficiency of the manufacturing process of continuous belts. For the purpose of verification of the design assumptions, the process has to be analysed together with further study of the influence of heating parameters on weld quality (Wałęsa et al., 2019a and 2019b). One of the basic research actions regarding this topic is to analyse the heat transfer during the hot plate welding process. To this end, it is required to identify the heat transfer phenomena taking place during hot plate welding. These considerations will consequently form the basis for performing temperature distribution calculations, which describe the temperature values at every point of the material, according to time. The results obtained from calculations and research, in combination with known material characteristics, will be used for calculating the plasticized distance. Identifying this value and its dependence on process variables (e.g., hot plate temperature, time and applied force) will be used to control the hot plate welding process. This allows to anticipate the extent of belt shortening throughout the manufacturing process and to determine the best parameters to obtain a satisfactory weld quality. Moreover, analysis of plasticized distance and temperature distribution will be used in the research regarding the influence of welding process to macrostructure of material. Thanks to this, the division for three heat affected zones, commonly expected for semi-crystalline material (Casalino and Ghorbel, 2008), will be verified. 
In addition, it should be noticed that a lot of thermal exchanging processes can be described in a mathematical way, especially using the FEM implements (Dyja et al., 2017; Gawrońska, 2019; Kubiak, 2019; Saternus et al., 2018 and 2019; Winczek et al., 2016). Considering the partial results of examinations of the plasticizing process and mechanical parameters derivation (Wałęsa et al., 2020a and 2020b), in further works, the hot plate welding process will be described by a mathematical model, which will take into consideration conclusions from the presented process analysis.

\section{THE HOT PLATE WELDING CYCLE}

Concerning the necessary technological operations, the hot plate welding process of the drive belts can be divided into five phases (Wałęsa et al., 2019a and 2019b; Klimpel, 2000; Potente et al., 2002; Jasiulek, 2006), with different physical phenomena occurring during the heat transfer in each phase. Considering this fact, the approximate temperature distribution can be expected (Potente et al., 2002). One of the most important activities is the plasticization of the belt end that enables the chemical reaction and physical interaction between the macromolecules in the joining process (Amanat et al., 2010; Amancio-Filho and dos Santos, 2009; Madej and Ozimina, 2010; Puszka, 2006; Żuchowska, 2000). The course of plasticization process conditions the rest of welding process, especially the ability of the ends of the belts to make durable joint during cooling step, where durable connections between macromolecules are made (Ciszewski and Radomski, 1989).

\subsection{The matching phase}

The first phase of welding is the matching of belt ends (Fig. 1). It entails plasticizing and melting the flat surfaces of the belt during their contact with the heated plate. The plate has the temperature $T_{p}$, which facilitates the welding process by gaining the welding temperature $T_{w}$ in the bonded material. The welding temperature choice is very important issue and its value depends on polymer type. Exceeding the degradation temperature causes destructing the material in a few stages (Wanqing et al., 2017). On the other hand, in case of some polymers, joint strength increases with welding temperature (Evers et al., 2017).

In matching phase, the belt ends (1) are held by shaped grips (2), and are moved towards the hot plate surface (3) with velocity $v_{m}$. After the surfaces of the belt and the hot plate make contact, the belt is pressed to the plate with force $F_{m}$. In this phase, flash is formed due to the belt plasticizing in contact with the hot plate. The partial melting results in the surface of the belt adapting to the surface shape of the hot plate. This is the result of the material's reaction to the temperature of the hot plate.

The belt heating causes the temperature to increase along its axis. Two main characteristic quantities can be therefore distinguished:

- the distance $p$, where belt temperature exceeds the welding temperature $T_{w}$ (the temperature when a material is plasticized and melted),

- the distance $h$, where belt temperature exceeds $T_{0}$.

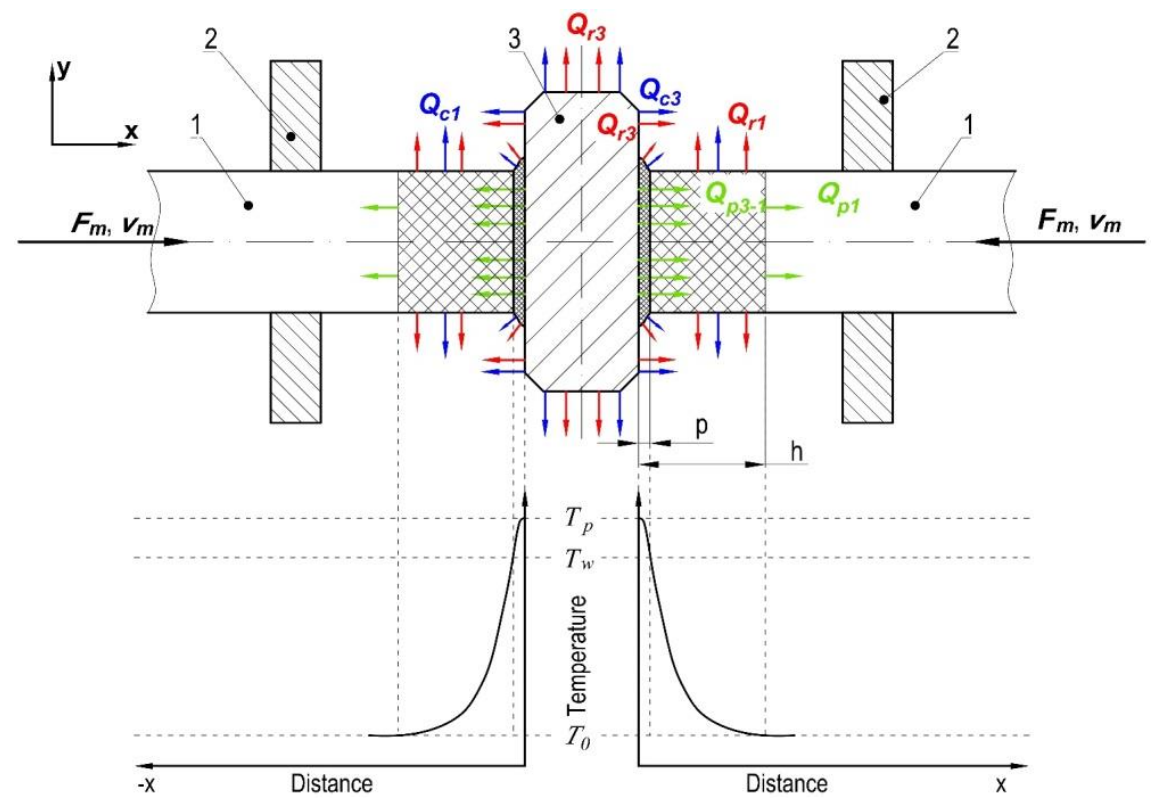

Fig. 1. The matching phase of the hot plate welding process with expected temperature distribution: $1-$ belt, $2-$ shaped grip, $3-$ hot plate, $F_{m}-$ matching force, $v_{m}$ - matching velocity, $T_{p}$ - the hot plate temperature, $T_{w}$ - welding temperature, $T_{0}$ - ambient temperature, $p$ - plasticize distance, $h$ - heating distance; $Q_{p 3-1}, Q_{p 1}, Q_{r 1}, Q_{r 3}, Q_{c 1}, Q_{c 3}$ - heat

During this phase, the following heat transfer phenomena are observed: conduction, convection and radiation. Considering the particular heat fluxes, the following can be identified:

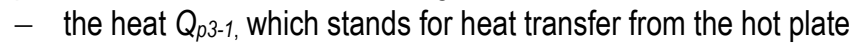
to the belt by contact conduction,

- the heat $Q_{p 1}$, which stands for heat transfer in the volume of the belt material through conduction,

- the heat $Q_{c 3}$, which stands for heat transfer from the hot plate through convection,

- the heat $Q_{r 3}$, which stands for heat transfer from the hot plate through radiation,

- the heat $Q_{c 1}$, which stands for heat transfer from the outer surface of the belt through convection,

- the heat $Q_{r 1}$, which stands for heat transfer from the outer surface of the belt through radiation. 
In this case, the dominant methods of heat transfer are: conduction in the belt material and contact conduction between the hot plate and the belt surface. The radiation is not as significant as the phenomena mentioned above, because the process temperature is relatively low. In further analysis, it is possible to disregard the issue of convection because the airflow around the belt or hot plate will be not forced; therefore, forced convection is not present. It is also possible to disregard natural convection during the analysis because the ends of the belt will be clamped in the shaped grips and dies, thus limiting the heat energy transfer to the cooler air.

The matching phase is very important. The melting of the belt surface as a result of hot plate contact allows matching the belt to the flat surface of the plate. Consequently, belt surfaces are placed parallel to each other and perpendicular to the central axis. Thus, the flat ends of the belt are properly aligned for bonding. The most important effect of material plasticizing is the removal of any inequalities, roughness and faults, which may have been incurred during the cutting process. This allows to avoid joint defect issues caused by inadequate surface preparation.

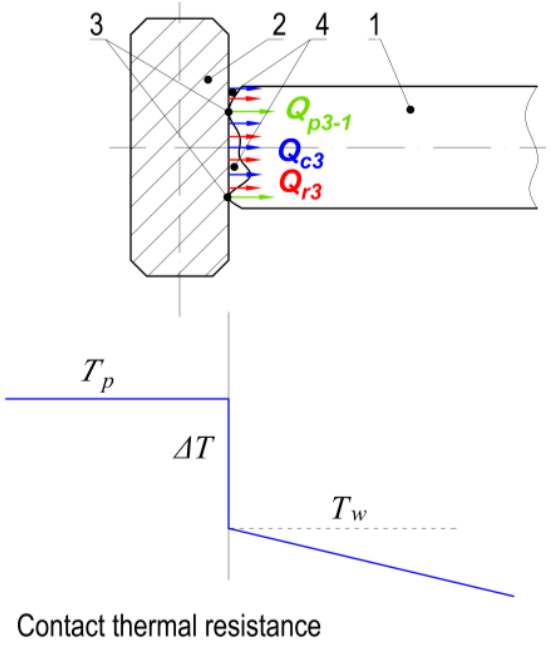

Fig. 2. Heating of the non-matched belt surface by the hot plate: 1 - belt, 2 - hot plate, 3 - contact points, 4 - cavities (filled by hot gases); $Q_{p 3-1}, Q_{r 3}, Q_{c 3}-$ heat

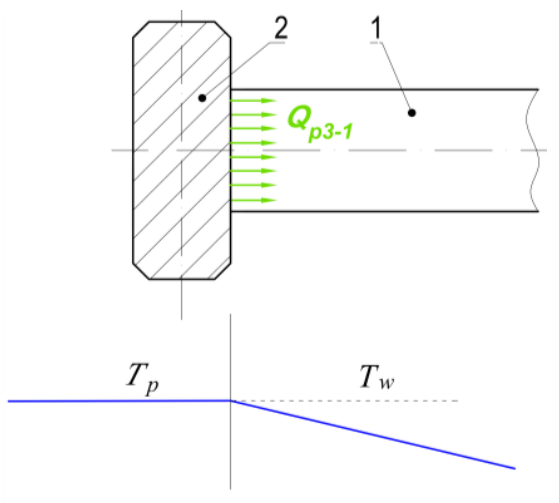

Ideal contact conductance

Fig. 3. Heating of the matched belt surface by the hot plate: $1-$ belt, 2 - hot plate; $Q_{p 3-1}$ - heat
Another benefit of the matching phase is providing uniform conditions for heat transfer along the whole flat surface of the belt (Amancio-Filho and dos Santos, 2009). This allows to replace the point thermal conduction $\left(Q_{p 3-1}\right)$, convection $\left(Q_{c 3}\right)$ and radiation $\left(Q_{r 3}\right)$ occurring through the cavities in the material (Fig. 2) with whole surface conduction $\left(Q p_{3-1}\right)$ resulting in more stable heat transfer conditions (Fig. 3).

\subsection{The heating phase}

During the heating phase (Fig. 4), the ends of the belt (1) are pressed against the hot plate (3) by the shaped grips (2) with force $F_{h}$. In this phase, the heat transfer phenomena are similar to the previous one. The area of the convection $\left(Q_{c 1}\right)$ and the radiation $\left(Q_{r 1}\right)$ effect is expanded. This is the result of the expansion of the heated area. Due to this fact, a new heat transfer mechanism occurs: conduction between the outer surface of the belt and shaped grips (Qp1-2).

The main assumptions of the heating phase are as follows:

- increase of the plasticized (melted) distance $p$ to the value ensuring the best conditions to perform the joining (chemical reactions and mechanical interactions between macromolecules), the increase in the $h$ distance is the side effect of the heating,

- the $F_{h}$ force value is significantly lower than the matching force $F_{m}\left(F_{h}\right.$ is about $10 \%-20 \%$ of $\left.F_{m}\right)$ because of the sharp decrease in polymer viscosity together with the increase in temperature (Klimpel, 2000). If too much clamping force is applied during the heating phase, it causes excessive flash formation. The first negative consequence is unnecessary loss of material. Secondly, the plasticized polymer is displaced from the joining area, which is disadvantageous because it can impede the joining process and form cavities in the central area of the joint. On the other hand, it is required to utilize a small value of $F_{h}$ force, as otherwise, issues with contact breaking might occur due to the outflow of material from the heating area. In this case, the belt ends should be pressed toward the hot plate, but this is impossible without applying $F_{h}$ force. It should be noticed that this action can be performed automatically owing to the thermal expansion of the belt material.

\subsection{The switchover phase}

The switchover phase consists in removing the hot plate from the area between the ends of the belt (Fig. 5).

The belt (1) is moved slightly by the shaped grips (2) to achieve a small clearance from the hot plate; however, this action can be disregarded in the heat transfer analysis. In this phase, the heating process ends, because of the source of energy is being withdrawn. Consequently, the switchover phase should be as short as possible. The convection $\left(Q_{c 1}\right)$ and the radiation $\left(Q_{r 1}\right)$ from the belt surfaces (especially in the flat surfaces of the weld) cause unnecessary loss of energy. Considering this fact, it is necessary to control the belt temperature, which has a tendency to decrease mainly in the flat, plasticized area. This is the result of the convection phenomenon, which becomes more significant with higher surface temperature. It is critical to maintain the temperature of the welding area greater than $T_{w}$. For this reason, the switchover time should be as short as possible. 


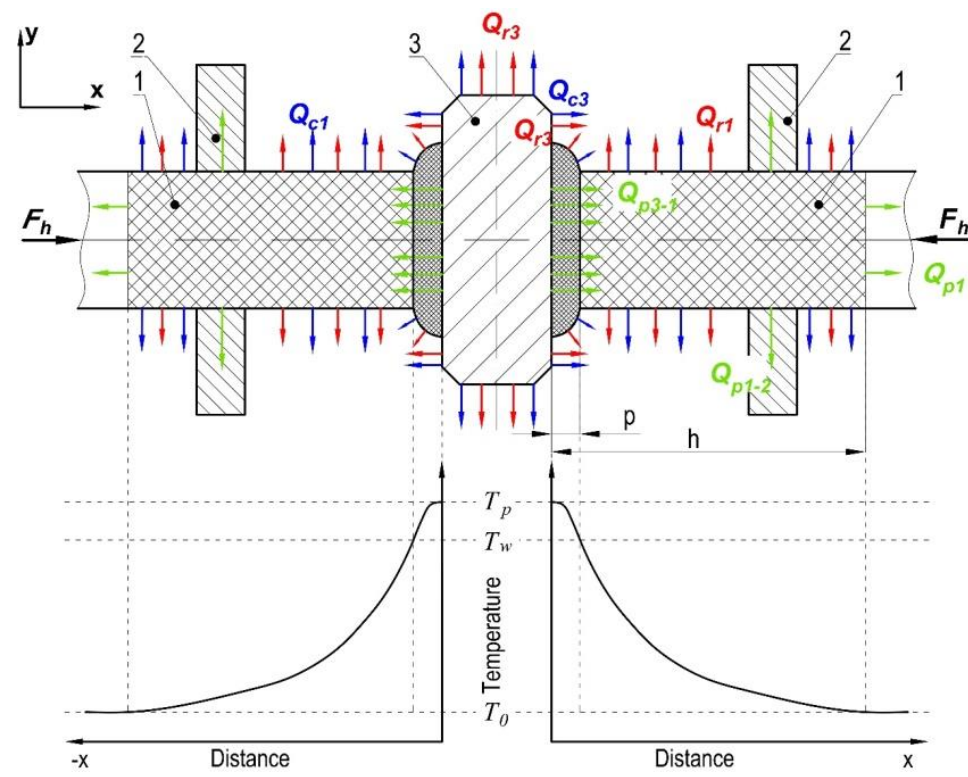

Fig. 4. The heating phase of the hot plate welding process with expected temperature distribution: 1 - belt, 2 - shaped grip, $3-$ hot plate, $F_{h}-$ force during heating, $T_{p}$ - the hot plate temperature, $T_{w}$-welding temperature, $T_{0}$ - ambient temperature, $p$ - plasticized distance, $h$ - heated region length; $Q_{p 3-1}$, $Q_{p 1-2}, Q_{p 1}, Q_{r 1}, Q_{r 3}, Q_{c 1}, Q_{c 3}$ - heat

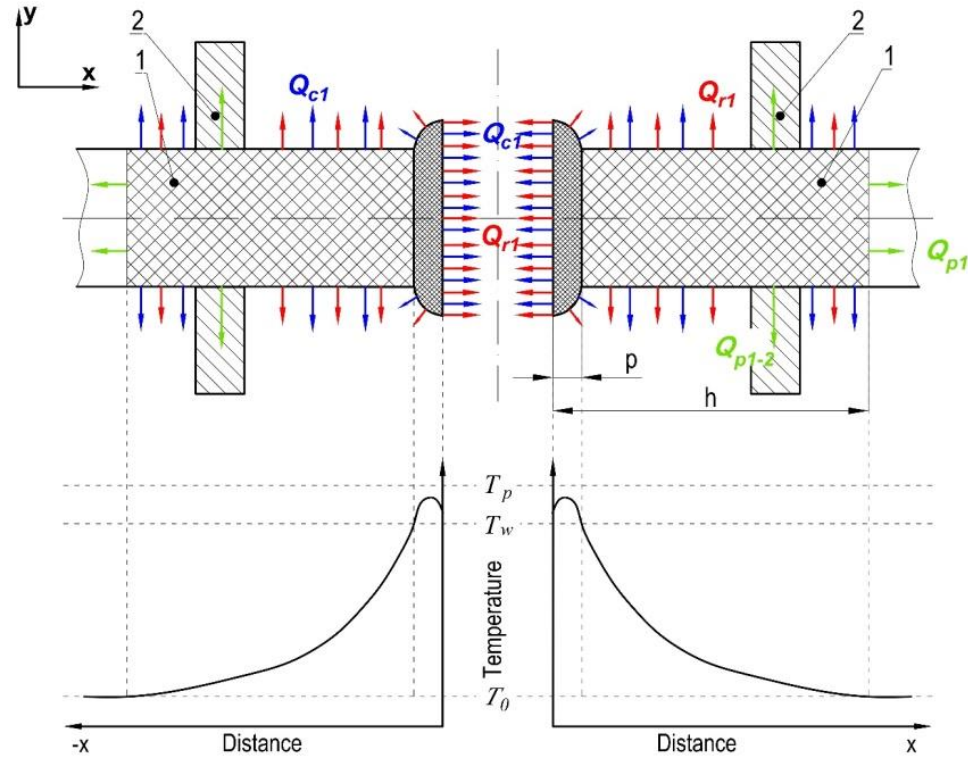

Fig. 5. The switchover phase of the hot plate welding process with expected temperature distribution: $1-$ belt, $2-$ shaped grip, $T_{p}-$ the hot plate temperature, $T_{w}$-welding temperature, $T_{0}$ - ambient temperature, $p$ - plasticize distance, $h$ - heated region length; $Q_{p 1-2,} Q_{p 1}, Q_{r 1}, Q_{c 1}-$ heat

\subsection{The joining phase}

In the joining phase, the ends of the belt (1) are clamped by shaped grips (2) and moved towards each other, which results in joining their surfaces (Fig. 6).

The joining phase is critical, because it is where the material bonding begins. It comprises two main characteristic phenomena:

- chemical reactions between molecules of the hydrocarbons,

- mechanical interactions between macromolecules which result in their splicing (Grewell and Benatar, 2007).

During the joining phase, one needs to consider a compromise between the short duration of the phase and low joining velocity $v_{j}$. The short phase time is associated with the relatively high velocity $v_{j}$, which is beneficial because of reduced energy loss by convection $\left(Q_{c 1}\right)$ and radiation $\left(Q_{r 1}\right)$. On the other hand, the joining velocity $v_{j}$ and the joining force $F_{j}$ should be as low as possible, to avoid the problem of excessive distortion of the plasticized region.

\subsection{The cooling phase}

In the cooling phase (Fig. 7), the ends of the belt (1) are pressed against each other. Free cooling occurs at the joint and the belt as a result of the interaction with the air surrounding the belt. In the ideal scenario, the duration of this activity should be sufficiently long, allowing the belt temperature to decrease to the level of ambient temperature $T_{0}$. Afterwards, the belt can be removed from the grips and the joint can be subject to further processing to remove the flash.

The main assumptions for the cooling phase are: 
- belt temperature is equalized by contact conduction,

- continuation of the chemical reactions and the mechanical interactions occurring between macromolecules,

- main heat transfer occurs through conduction $\left(Q_{p 1}\right)$ in the material,

- heat transfer with the environment only occurs via natural convection $\left(Q_{c 1}\right)$ and radiation $\left(Q_{r 1}\right)$,

- the duration of this step depends on belt temperature - its value should decrease to the level of ambient temperature $T_{0}$ at the end of the phase.

The cumulative hot plate welding process time, ranging from over a dozen seconds to a few dozen minutes (Cocard et al., 2009), depends on the dimensions of the welded parts. Usually, the longest is the cooling phase (Klimpel, 2000).

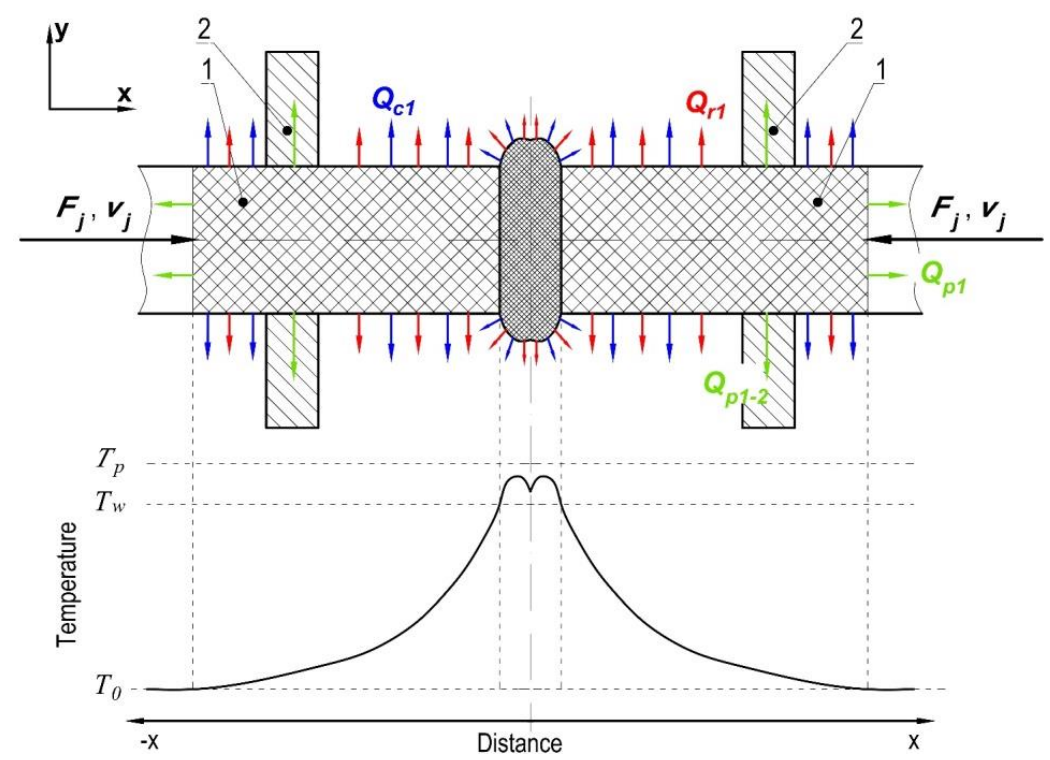

Fig. 6. The joining phase of the hot plate welding process with expected temperature distribution: $1-$ belt, 2 - shaped grip, $F_{j}-$ joining force, $v_{j}-$ joining velocity, $T_{p}$ - the hot plate temperature, $T_{w}$-welding temperature, $T_{0}$ - ambient temperature, $p$ - plasticize distance, $h$ - heated region length; $Q_{p 1-2,}$ $Q_{p 1}, Q_{r 1}, Q_{c 1}$ - heat

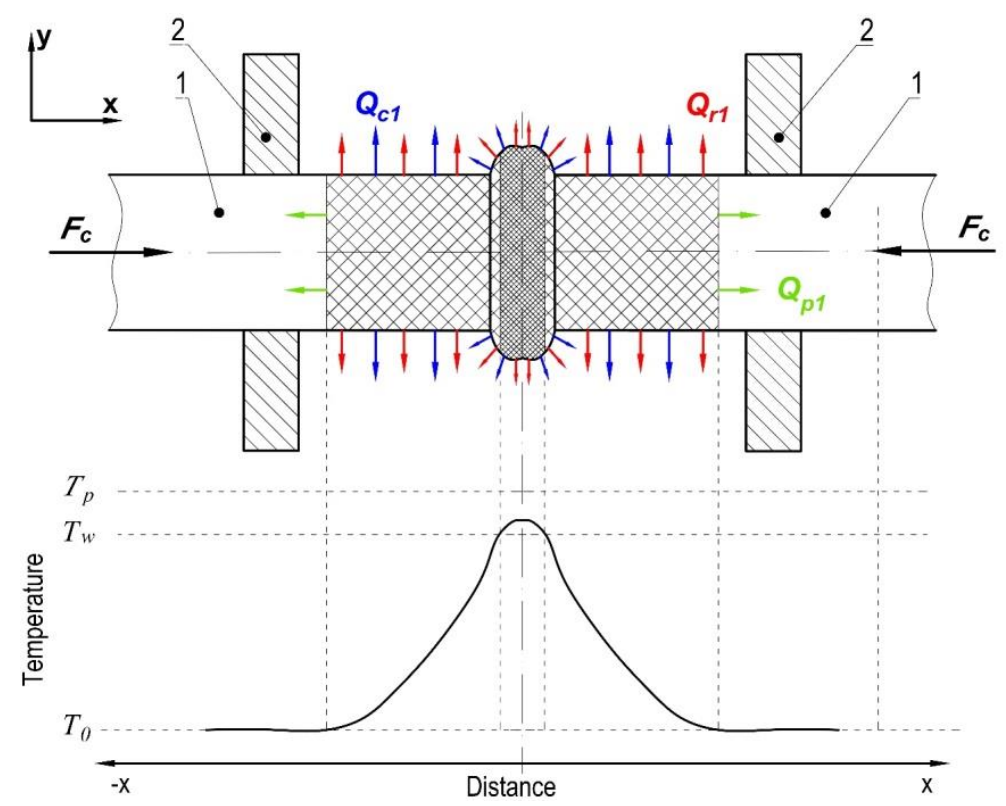

Fig. 7. The cooling phase of the hot plate welding process with expected temperature distribution: $1-$ belt, $2-$ shaped grip, $F_{c}-$ force during cooling, $T_{p}-$ the hot plate temperature, $T_{w}$-welding temperature, $T_{0}$ - ambient temperature, $Q_{p 1}, Q_{r 1}, Q_{c 1}-$ heat

\section{MODELLING OF THE HEAT TRANSFER PHENOMENA}

The complete analysis of the hot plate welding process calls for establishing temperature distribution. This function describes the temperature values at all the points of the heated region, according to time (Carslaw and Jaeger, 1959). To obtain this derivation, it is necessary to solve the heat transfer equations. 


\subsection{Simplifications regarding the heat transfer phenomena}

To simplify analysing the heat transfer process in preliminary description of the hot plate welding process, some factors can be omitted. Furthermore, several assumptions can be made for the purpose of performing the mathematical calculation:

- the transient heat transfer during the entire process, that is, the temperature in every point of the belt changes throughout the process duration,

- belt as a long body, with high length to diameter ratio,

- uniform temperature distribution in the belt cross section, because the belt material is homogeneous in the macro scale; therefore, it can be treated as isotropic,

- the phenomenon of heat generation is not present,

- considering the heat transfer along the main axis of the belt as unidimensional, heated from a flat surface together as well as the isotropic model of the material,

- heating of both ends of the belt is symmetrical,

- disregarding natural convection from the outer surface of the belt and the hot plate, because the airflow is not forced, and therefore, natural convection is not a significant factor,

- omitting the radiation from the outer surface of the belt and the hot plate. This assumption is based on the relatively low temperature and a short time,

- disregarding heat conduction from the belt to shaped grips, which are a relatively long distance away from the heating area, and therefore, their contribution is not significant,

- constant hot plate temperature on the whole surface, this allows to simplify the issue because the temperature change due to the energy transfer can be omitted,

- disregarding the effect of thermal expansion,

- density, heat transfer coefficient and specific heat of the belt are not dependent on temperature. Considering the preliminary calculations, we can assume that these parameters do not vary with temperature increase,

- the hot plate is a rigid and non-deformable body.

These assumptions can be made, due to relatively low process temperature, which does not exceed $300^{\circ} \mathrm{C}$ (Wałęsa et al., $2019 \mathrm{~b}$ and 2020a). These simplifications allow to perform the calculation on temperature distribution taking into consideration the commonly known heat transfer cases, that is, the semi-infinite space, the round rod placed between the walls or the round ribs (Carslaw and Jaeger, 1959).

\subsection{Possibilities of mathematical modelling}

The heat transfer in almost every phase of hot plate welding is primarily through conduction. Considering this fact, it is required to solve the heat conduction equation (1). In general case, it takes the following form (Staniszewski, 1979):

$\frac{\partial}{\partial x}\left(\lambda \frac{\partial T}{\partial x}\right)+\frac{\partial}{\partial y}\left(\lambda \frac{\partial T}{\partial y}\right)+\frac{\partial}{\partial z}\left(\lambda \frac{\partial T}{\partial z}\right)+q_{v}=c_{p} \cdot \rho \cdot \frac{\partial T}{\partial t}$.

Using the simplifications mentioned above, it can be assumed that: thermal conductivity $(\lambda)$, latent heat $\left(c_{p}\right)$ and density $(\rho)$ are constant within the whole temperature range. Moreover, internal heat generation $\left(q_{v}\right)$ can be omitted. Consequently, the simplified Fourier's equation (2), shall have the following form:

$a \cdot \nabla^{2} T=\frac{\partial T}{\partial t}$, where: a stands for thermal diffusivity, described in equation:

$a=\frac{\lambda}{c_{p} \cdot \rho}$.

Assuming the unidimensional character allows to further simplify equation (2) to achieve the following form:

$a \cdot \frac{\partial^{2} T}{\partial x^{2}}=\frac{\partial T}{\partial t}$.

The solution of this differential equation is not obvious, and its form depends on the starting and boundary condition. For the matching and heating phase, it can utilize the first type of boundary conditions, where the value of the hot plate and the ambient temperature is set. The temperature distribution in switchover phase can be simplified by transferring the coordinates of heating temperature distribution. For the joining and cooling phase, it is required to use the third type boundary condition in the following form (Carslaw and Jeager, 1959):

$\frac{\partial T(x, t)}{\partial x}=-\frac{\alpha}{\lambda} \cdot T(x, t)$,

where: $\alpha$ is the heat transfer coefficient.

Obviously, other assumptions may be made as well. For example, it is possible to account for melting. In this case, thermodynamic constants $\left(\alpha, \lambda, c_{p}\right)$ and density $(\rho)$ will be different in solid and liquid phase (Taler and Duda, 2003). This fact calls for further analysis.

\section{SUMMARY}

We distinguish the following heat transfer phenomena that are of key importance for the hot plate welding process: conduction, convection and radiation. It is necessary to analyse their specific parameters for each phase of the hot plate welding. Considering the phenomena in particular, together with employing a number of simplifications allows to derive the temperature distribution, which describes the temperature in every point along the belt axis. This function is to be solved analytically and the results will be examined by FEM implements. Afterwards, it is anticipated that experimental research should allow to verify the model.

The temperature distribution along the axis of the belt, together with the known material characteristics, will be used to establish the plasticized area of the belt as well as the shortening of the belt during the hot plate welding process.

After preliminary analysis, with listed simplifications of heat transfer modelling, authors will make an effort to the estimate radiation and convection coefficients. After that, the temperature distribution results will be compared with calculations regarding simplifications, to obtain precisely described temperature distribution, and real error of calculations with simplifications.

\section{REFERENCES}

1. Amanat N., James N. L., McKenzie D.R. (2010), Welding methods for joining thermoplastic polymers for the hermetic enclosure of medical devices, Medical engineering \& Physics, 32, 690-699.

2. Amancio-Filho S.T., dos Santos J.F. (2009), Joining of Polymers and Polymer-Metal Hybrid Structures: Recent Developments and Trends, Polymer Engineering and Science, 49(8), 1461-1476.

3. Behabelt (2015), Product Catalogue 2015/2016, Behabelt, Glottertal.

4. Carslaw H.S., Jeager J.C., 1959, Conduction of Heat in Solids, Oxford University Press, London. 
5. Casalino G., Ghorbel E. (2008), Numerical model of $\mathrm{CO}_{2}$ laser welding of thermoplastic polymers, Journal of Materials Processing Technology, 207, 63-71.

6. Ciszewski A., Radomski T. (1989), Constructuion materials in machine design (in Polish), PWN, Warszawa.

7. Cocard M., Grozav I., lacob M., Caneparu A. (2009), Establishing the Optimum Welding Procedure for PE 100 Polyethylene Pipelines Using the Response Surface Design, Materiale Plastice, 46(4), 452-457.

8. Domek G., Dudziak M. (2011), Energy Dissipation in Timing Belts Made From Composite Materials, Advanced Material Research, 189-193, 4414-4418.

9. Domek G., Kołodziej A., Dudziak M., Woźniak T. (2016), Identification of the quality of timing belt pulleys, Procedia Engineering, 177, 275-280.

10. Dyja R., Gawrońska E., Grosser A. (2017), Numerical problems related to solving the Navier-Stokes equations in connection with the heat transfer with the use of FEM, Procedia Engineering, 177, 78-85.

11. Evers F., Schöppner V., Lakemeyer P. (2017), The influence on welding processes on the weld strength of flame-retardant materials, Weld World, 61, 161-170.

12. Gawrońska E. (2019), A sequential approach to numerical simulations of solidification with domain and time decomposition, Applied Sciences, 9(10).

13. Grewell D., Benatar A. (2007), Welding of plastics: fundamentals and new developments, International Polymer Processing, 22(1), 43-60.

14. Groover M. P. (2015), Fundamentals of modern manufacturing, Willey, 503-510.

15. Inoue T., Miyata R., Hirai S. (2016), Antagonistically Twisted Round Belt Actuator System for Robotic Joints, Journal of Robotics and Mechatronics, 28(6), 842-853.

16. Jasiulek P. (2006), Joining of plastics by welding, glueing and laminating (in Pollish), Wydawnictwo 'KaBe', Krosno.

17. Klimpel A. (2000), Welding of termoplastics materials (in Polish), Wydawnictwo Politechniki Śląskiej, Gliwice.

18. Krawiec P., Grzelka M., Kroczak J., Domek G., Kołodziej A (2019), A proposal of measurement methodology and assessment of manufacturing methods of nontypical cog belt pulleys, Measurement, 132, 182-190.

19. Krawiec P., Waluś K., Warguła Ł., Adamiec J. (2018), Wear evaluation of elements of $\mathrm{V}$-belt transmission with the application of the optical microscope, MATEC Web of Conferences, 157, 01009 .

20. Krishnan C., Benatar A. (2004), Analysis of Residual Stress in Hot Plate Welded Polycarbonate, ANTEC 2004 Proceedings: Plastics, 1149-1153.

21. Kubiak M. (2019), Prediction of microstructure composition in steel plate heated using high power Yb:YAG laser radiation, MATEC Web of Conferences, 254, 02023.

22. Kukla M., Tarkowski P., Górecki J., Malujda I., Talaśka K. (2015), The Effect of Magnetic Field on Magnetorheological Composites. Artificial Neural Network Based Modelling and Experiments, Applied Mechanics And Materials, 816, 327-336.

23. Madej M., Ozimina D. (2010), Plastics and composite materials (in Polish), Wydawnictwo Politechniki Świętokrzyskiej, Kielce.

24. Mokhtarzadeh A., Benatar A. (2012), Experiments with conventional and high temperature hot plate welding of thermoplastics using temperature and pressure control, ANTEC 2012 Proceedings: Plastics, 1684-1690.

25. Nieh J., Lee J. (1992), Hot Plate Welding of Polypropylene Part I: Crystallization Kinetics, Polymer Engineering and Science, 38 1121-1132.

26. Potente H., Schneiders J., Bornemann M. (2002), Theoretical model for the one-dimensional temperature and stress calculation of simple hot plate welded geometries, Macromolecular Materials and Engineering, 287, 843-853.
27. Puszka A. (2006), Polyurethanes - sources, properties and modifications (in Polish), Zakład Chemii Polimerów, Wydział Chemii Uniwersytetu Marii Curie Skłodowskiej w Lublinie, Lublin.

28. Rzasinski R. (2017), The algorithm of verification of welding process for plastic pipes, IOP Conference Series: Materials Science and Engineering, 227, 012113.

29. Saternus Z., Piekarska W., Kubiak M., Domański T. Goszczyńska-Króliszewska D. (2018), Numerical estimation of temperature field in a laser welded butt joint made of dissimilar materials, MATEC Web of Conferences, 157, 02043.

30. Saternus Z., Piekarska W., Kubiak M., Domański T., Goszczyńska-Króliszewska D. (2019), Numerical modeling of cutting process of steel sheets using a laser beam, MATEC Web of Conferences, 254, 08004

31. Sikora R. (1993), Polymers processing (in Polish), Wydawnictwo ŻAK, Warszawa.

32. Staniszewski B., 1979, Wymiana Ciepła Podstawy Teoretyczne, PWN, Warszawa

33. Taler J., Duda P., 2003, Rozwiązywanie prostych i odwrotnych zagadnień przewodzenia ciepła, Wydawnictwo Naukowo - Techniczne, Warszawa.

34. Troughton M. (1997), Handbook of Plastics Joining: A practical guide, Plastics Design Library, New York.

35. Wałęsa K., Malujda I., Górecki J. (2020), Experimental research of the mechanical properties of the round drive belts made of thermoplastic elastomer, IOP Conference Series: Materials Science and Engineering, 776, 012107.

36. Wałęsa K., Malujda I., Talaśka K. (2018), Butt welding of round drive belts, Acta Mechanica et Automatica, 12(2), 115-126.

37. Wałęsa K., Malujda I., Wilczyński D. (2020), Experimental research of the thermoplastic belt plasticizing process in the hot plate welding, IOP Conference Series: Materials Science and Engineering, 776, 012011

38. Wałęsa K., Malujda M., Górecki J., Wilczyński D. (2019), The temperature distribution during heating in hot plate welding process, MATEC Web of Conferences, 254, 02033.

39. Wałęsa K., Mysiukiewicz O., Pietrzak M., Górecki J., Wilczyński D. (2019), Preliminary research of the thermomechanical properties of the round drive belts, MATEC Web of Conferences, 254, 06007.

40. Wanqing L., Changqing F., Xing Z., Youliang C., Rong Y., Donghong L. (2017), Morphology and thermal properties of polyurethane elastomer based on representative structural chain extenders, Thermochimica Acta, 653, 116-125

41. Wilczyński D., Malujda M., Górecki J., Domek G. (2019), Experimental research on the proces of cutting transport belts, MATEC Web of Conferences, 254, 05014.

42. Winczek J., Modrzycka A., Gawrónska E. (2016), Analytical description of the temperature field induced by laser heat source with any trajectory, Procedia Engineering, 149, 553-558.

43. Wojtkowiak D., Talaśka K. (2019), Determination of the effective geometrical features of the piercing punch for polymer composite belts, The International Journal of Advanced Manufacturing Technology, 104(1-4), 315-332.

44. Wojtkowiak D., Talaśka K., Malujda I., Domek G. (2018), Estimation of the perforation force for polimer composite conveyor belts taking into consideration the shape of the piercing punch, The International Journal of Advanced Manufacturing Technology, 98(912), 2539-2561.

45. Yousepour A., Hojjari M., Immarigeon J-P. (2004), Fusion Bonding/Welding of Thermoplastic Composites, Journal of Thermoplastic Composite Materials, 17, 303-341.

46. Żuchowska D. (2000), Construction polymers (in Polish), WNT, Warszawa. 